\title{
PENGARUH MANAJEMEN MUTU LAYANAN TERHADAP KEPUASAN PESERTA DIDIK
}

\section{The Effect of Quality Management Services on the Satisfaction of Participants}

\author{
Yandri Sudodo ${ }^{1}$ \\ ${ }^{1}$ Program Studi Manajemen, Fakultas Ekonomi dan Bisnis Universitas Teknologi Sumbawa \\ e-mail : yandrisudodo@gmail.com
}

\begin{abstract}
The objective of this study is to understand the effect of the service quality on the satisfaction of Madrasah Aliyah Negeri 1 Sumbawa Besar students. Samples in this research are 200 students which was chosen by random sampling technique. The data was obtained through questionnair that had been tried out and had met the validity and reliability requirement with Cronbach Alpha technique and analyzed by the multivariable regression analysis. The significance level is 5\%. The results show that: (1) the reliability service does not have a significant effect on the student's satisfaction $(t=1.729 ; p=0.085)$. (2) The responsiveness service does not have a significant effect on the student's satisfaction ( $t$ $=1.917 ; p=0.057)$. (3) The assurance service has a positive and significant effect on the student's satisfaction ( $t=$ 2.064; $p=0.040)$. (4) The empathy service has a positive and significant effect on the student's satisfaction ( $t=2.703$; $p=0.007)$. (5) The tangible service has a positive and significant effect on the student's satisfaction $(t=9.020 ; p=$ 0.000). (6) The reliability service, responsiveness service, the assurance service, the empathy service, and tangible service have a significant effect altogether on the student's satisfaction $(F=50.026 ; p=0.000)$.
\end{abstract}

Keywords: Reliability Service, Responsiveness Service, Assurance Service, Empathy Service, Tangible Service, Students Satisfaction.

\begin{abstract}
ABSTRAK
Penelitian ini bertujuan untuk mengetahui pengaruh pelayanan mutu terhadap kepuasan siswa Madrasah Aliyah Negeri 1 Sumbawa Besar. Sampel dalam penelitian ini berjumlah 200 siswa yang dipilih menggunakan teknik random sampling. Data diperoleh melalui kuesioner yang telah diujicobakan dan telah memenuhi persyaratan validitas dan reliabilitas dengan teknik Alpha Cronbach dan dianalisis dengan analisis regresi berganda. Tingkat signifikansi adalah 5\%. Hasil analisis regresi berganda menunjukkan: (1) pelayanan keandalan tidak berpengaruh signifikan terhadap kepuasan siswa $(t=1,729 ; p=0,085)$. (2) Pelayanan responsif tidak berpengaruh signifikan terhadap kepuasan responden $(t=1.917 ; p=0,057)$. (3) Pelayanan penjaminan memiliki pengaruh positif dan signifikan terhadap kepuasan siswa $(t=2,064 ; p=0,040)$. (4) Pelayanan empati memiliki pengaruh positif dan signifikan terhadap kepuasan siswa $(t=2.703 ; p=0,007)$. (5) Pelayanan berwujud memiliki pengaruh positif dan signifikan terhadap kepuasan siswa $(t=9.020 ; p=0.000)$. (6) Layanan keandalan, layanan responsif, layanan jaminan, layanan empati, dan layanan nyata berpengaruh secara signifikan terhadap kepuasan siswa $(F=50,026 ; p=0,000)$.
\end{abstract}

Kata Kunci: Pelayanan Keandalan, Pelayanan Responsif, Pelayanan Kepastian, Pelayanan Empati, Pelayanan Berwujud, Kepuasan Peserta Didik.

\section{Pendahuluan}

Sejalan dengan memuncaknya persaingan kualitas dan kuantitas antar SMA, SMK, dan Madrasah Aliyah yang sangat kompetitif dalam dekade akhir-akhir ini, Madrasah Aliyah dituntut untuk tetap berkualitas, baik dipandang oleh insan di lingkungan internal itu sendiri maupun oleh insan eksternal atau di luar lingkungan madrasah aliyah yang bersangkutan. Kualitas dapat dipandang dari dua perspektif internal dan eksternal (Payne, 2000 : 272). Kualitas internal didasarkan pada kesesuaian dengan spesifikasi yang dimiliki tiap lembaga atau organisasi pendidikan yang dalam hal ini adalah Madrasah. Kualitas eksternal didasarkan pada kualitas yang dipersepsikan siswa relatif. Poin yang penting adalah bahwa kualitas harus dilihat dari sudut pandang siswa, bukan dari organisasi. Oleh karena itu, kualitas harus diukur dari perspektif siswa, bukan apa yang dianggap oleh para pimpinan didalam organisasi yang merupakan pandanganpandangan siswa mereka. Perkembangan dan peningkatan kualitas pendidikan dari tahun ke tahun semakin menjadi perhatian masyarakat. Hal ini dapat dilihat dari ketatnya persaingan kualitas layanan, harga, promosi diantara sekian sekolah ataupun madrasah. Dalam kondisi persaingan yang ketat tersebut, hal 
utama yang harus diprioritaskan oleh madrasah aliyah adalah kepuasan peserta didik. Pimpinan harus tahu hal-hal apa saja yang dianggap penting oleh para peserta didik dan pimpinan berusaha untuk menghasilkan kinerja sebaik mungkin sehingga dapat memuaskan para peserta didiknya. Kepuasan peserta didik ditentukan oleh kualitas yang dikehendaki peserta didik, sehingga jaminan kualitas menjadi prioritas utama bagi setiap sekolah atau madrasah yang pada saat ini khususnya dijadikan sebagai tolok ukur keunggulan daya saing.

Saat ini, dunia pendidikan Indonesia secara umum mengalami permasalahan pelik yang menjadi keprihatinan nasional. Hal ini menyangkut sejauh mana sekolah atau madrasah aliyah bersangkutan tetap setia dan sungguh-sungguh berjuang mewujudkan idealismenya ditengah budaya pendidikan instan yang tengah berkembang. Persoalan ini bertambah kompleks seiring dengan arus globalisasi yang ditandai dengan perkembangan teknologi informasi. Keseluruhannya ini berdampak pada semakin mendesaknya kebutuhan untuk melakukan reformasi, khususnya menyangkut produk (misalnya kurikulum dan program studi yang ditawarkan), proses (administrasi, registrasi, belajar mengajar, dan lainlain), jasa (fasilitas akademik dan non akademik) dan lingkungan (peka terhadap masalah sosial, etika, dan lingkungan hidup). Tidak kalah pentingnya adalah bahwa sekolah atau madrasah harus bisa memberikan kesamaan kesempatan (equality of opportunity) kepada setiap siswa untuk mengembangkan diri sesuai dengan kemampuannya. (Dros, 1998 dalam Tjiptono dan Diana 2005 : 37). Sebagaimana lembaga pendidikan pada umumnya, Madrasah Aliyah Negeri 1 Sumbawa besar menghadapi tantangan yang semakin berat sejalan dengan perubahan masyarakat karena pengaruh globalisasi. Untuk meningkatkan kualitas pengelolaan proses pembelajaran yang mampu menghasilkan lulusan yang berkualitas, maka perlu diadakan tindakan dan kajian terhadap manajemen mutu layanannya, agar tetap terjaga kemutakhiranan pelayanan dan menjamin agar secara efektif mampu memenuhi kebutuhan para peserta didiknya. Sekolah atau madrasah sebagai salah satu bentuk penyedia jasa yang melibatkan tingkat interaksi yang tinggi antara penyedia dan pemakai jasa, menurut Tjiptono dan Diana (2003 : 27) terdapat lima kriteria penentu kualitas jasa layanan, yaitu kehandalan (reliability), daya tanggap (responsiveness), jaminan (assurance), perhatian individu (empathy), dan bukti fisik (tangible). Pertama, kehandalan yaitu kemampuan dalam memberikan pelayanan yang dijanjikan dengan segera dan tepat waktu, akurat, dan memuaskan. Kedua, daya tanggap yaitu kesediaan para staf untuk membantu para peserta didik dan memberikan pelayanan dengan tanggap. Ketiga, jaminan yaitu mencakup kemampuan, kesopanan, dan sifat dapat dipercaya yang dimiliki para staf (staf pengajar, asisten, dan staf administrasi) bebas dari bahaya, resiko, atau keragu-raguan. Keempat, empati meliputi kemudahan dalam melakukan hubungan, komunikasi yang baik, dan memahami kebutuhan para peserta didik seperti kemudahan guru untuk dihubungi baik di ruang kerja, via telepon, $e$ mail, dan sebagainya. Terakhir kelima, adanya bukti fisik yang meliputi fasilitas fisik, perlengkapan, staf administrasi dan pengajar, serta sarana komunikasi. Komponen kualitas jasa pelayanan pada industri jasa pendidikan ini tidak cukup hanya sekedar pada macam atau jenis pelayanan yang diberikan, tetapi juga sangat tergantung pada proses pengelolaan dan pemberian pelayanan.

Menurut Zammuto et al. (2008) dikatakan bahwa: "As a result, if an organization regularly provides service at a level that exceeds customer expectations, the service will be evaluated as high quality. In contrast, if an organization fails to meet customer expectations, the service will be judge as poor quality." Artinya jika sebuah organisasi teratur menyediakan layanan pada tingkat yang melebihi harapan pelanggan, layanan ini akan dievaluasi sebagai kualitas tinggi. Sebaliknya, jika suatu organisasi gagal memenuhi harapan pelanggan, layanan ini akan menjadi hakim sebagai kualitas yang buruk. Selain itu, menurut Lewis and Booms (1983) menyatakan bahwa "Service quality is a measure of how well the service level delivered matches customer expectations. Delivering quality service means conforming to customer expectations on a consistent basis." Artinya kualitas layanan adalah ukuran dari seberapa baik tingkat layanan yang disampaikan sesuai harapan pelanggan. Memberikan layanan berkualitas berarti sesuai dengan harapan pelanggan secara konsisten.

Manajemen jasa yang semula berorientasi pada sektor manufaktur telah bergeser ke arah orientasi yang lebih luas dengan melibatkan aspek jasa atau layanan. Dalam dunia akademik, perkembangan manajemen jasa ini telah mendorong berbagai sekolah dan madrasah aliyah untuk menerapkannya, baik dalam pengelolaannya terhadap para peserta didiknya maupun dalam memberikan jasa layanannya. Hal ini karena peran strategik manajemen jasa semakin diakui dan bukan hanya terbatas pada konteks tradisional industri jasa atau sektor jasa semata, sehingga perspektif jasa semakin banyak diadopsi dan diimplementasikan kedalam berbagai organisasi, baik organisasi manufaktur maupun organisasi jasa seperti jasa pendidikan. Schneider dalam Tjiptono (2003: 50) menegaskan bahwa manajemen jasa merupakan bidang multidisiplin praktek dan riset berkenaan dengan kualitas jasa. Fokus dari manajemen jasa ini adalah pada pemahaman atas cara-cara mengelola pada proses penyampaian jasa layanan. Konsep jasa layanan lebih menekankan aspek praktek, kebijakan dan prosedur layanan sebuah organisasi, sehingga 
manajemen mutu layanan dalam organisasi pendidikan memiliki komitmen untuk mencapai kepuasan peserta didik. Sebagai paradigma manajerial baru, manajemen mutu layanan telah banyak diterapkan dalam lembaga-lembaga pendidikan. Dalam pelaksanaannya telah menempatkan pandangan bahwa produk pendidikan adalah berbentuk jasa layanan pendidikan yang diberikan oleh pengelola pendidikan kepada siswa sesuai standar mutu. Terdapat banyak faktor yang mempengaruhi mutu pendidikan, seperti pemeliharaan gedung yang baik, guru-guru yang profesional, nilai moral yang tinggi, hasil ujian yang unggul, penerapan teknologi, kekuatan kepemimpinan, pemeliharaan dan perhatian terhadap peserta didik, kurikulum yang tepat, atau perpaduan berbagai faktor. Oleh karena itu, manajemen mutu layanan ini merupakan strategi pengelolaan mutu yang terlibat dalam pengadaan dan penyajian jasa pendidikan yang dijiwai oleh motivasi dan sikap untuk memenuhi dan memuaskan harapan siswa. Tujuan dari manajemen mutu layanan ini adalah untuk menyesuaikan kebutuhan dan keinginan siswa (Sallis, 2007: 34). Kepuasan siswa merupakan faktor esensial dalam manajemen mutu, karena itu sekolah dan madrasah harus mengidentifikasi para siswa dan kebutuhan mereka secara cermat, serta berusaha memuaskannya.

Menurut Sa'ud (2008:85) keberhasilan lembaga persekolahan dapat dilihat dari sudut dan tingkat kepuasan dari pelanggannya, yaitu pelanggan sekolah yang dikategorikan pelanggan internal maupun pelanggan eksternal. Hal ini memberikan arti bahwa ukuran sebuah keberhasilan sekolah dapat dilihat dari layanan yang diberikannya. Apakah layanan yang diberikan itu berada pada taraf yang sama atau sesuai dengan harapan pelanggan atau bahkan melebihi, seperti apa yang diharapkan oleh pelanggannya. Selain itu, Alma (2008:13) mengemukakan bahwa apabila kita melihat lembaga pendidikan dari kacamata sebuah corporate, maka lembaga pendidikan ini adalah suatu organisasi produksi yang menghasilkan jasa pendidikan yang dibeli oleh para konsumen. Maka dari itu, lembaga pendidikan ini seyogianya memperhatikan kepuasan dari pelanggan itu sendiri yaitu peserta didik/ siswa, kinerja lembaga dan mutu layanan dari lembaga tersebut. Sedangkan Sopiatin (2010:33) mengemukakan bahwa kepuasan siswa adalah suatu sikap positif siswa terhadap pelayanan proses belajar mengajar yang dilaksanakan oleh guru karena adanya kesesuaian antara apa yang diharapkan dan dibutuhkan dengan kenyataan yang diterimanya.

Pada prosesnya, sebab-sebab timbulnya ketidak puasan menurut Sopiatin (2010:34) diantaranya adalah (1) tidak sesuainya antara harapan siswa dengan kenyataan yang dialaminya, (2) layanan pendidikan yang diterima siswa tidak memuaskan, (3) perilaku personil sekolah yang kurang menyenangkan, (4) suasana dan kondisi fisik bangunan dan lingkungan sekolah yang tidak menunjang untuk belajar, (5) kegiatan ekstrakulikuler sekolah yang tidak menarik, (6) prestasi siswa yang rendah.

\section{Metode Penelitian}

Dalam penelitian ini dilibatkan 5 (lima) variabel bebas dan 1 (satu) variabel terikat. Variabel bebas meliputi: layanan yang handal, layanan yang responsif, layanan yang meyakinkan, layanan yang empatis, dan layanan penyediaan fasilitas, sedangkan variabel terikat adalah kepuasan peserta didik. Teknik analisis data dalam penelitian ini adalah menggunakan teknik analisis data kuantitatif. Sebelum dilakukan analisis data maka data yang dikumpulkan diolah terlebih dahulu agar siap untuk dianalisis. Tahapan pengolahan data yang diterapkan dalam penelitian ini adalah entri data atau memasukkan data merupakan proses mengumpulkan informasi yang telah diperoleh kedalam media agar informasi tersebut bisa dimanipulasi dan dibaca. Sebelum melakukan analisis data yang lebih lanjut maka data diolah terlebih dahulu dengan menggunakan tabel frekuensi dan statistik deskriptif.

Jika nilai nilai level of significance $t_{\text {hitung }}$ menurut hasil perhitungan lebih besar daripada 0,05, maka $\mathrm{H}_{0}$ diterima dan $\mathrm{H}_{1}$ ditolak. Artinya, tidak ada pengaruh secara parsial variabel bebas terhadap variabel terikat.

\section{Hasil Penelitian dan Pembahasan}

Dalam penelitian ini digunakan teknik analisis regresi ganda yaitu untuk mengetahui pengaruh layanan yang handal, layanan yang responsif, layanan yang meyakinkan, layanan yang empatis, dan layanan penyediaan fasilitas terhadap kepuasan peserta didik. Besarnya pengaruh ditunjukkan oleh koefisien regresinya. Secara keseluruhan menunjukkan R2 sebesar 0,$563 ; \mathrm{F}=50,026$ dengan probabilitas 0,000 . Hal ini berarti terdapat pengaruh signifikan variabel dependen (kepuasan peserta didik) dengan semua variabel independen (variasi prediktornya).

Hasil analisis regresi ganda yang dilakukan dengan bantuan komputer program SPSS 10.0 for Windows dirangkum dalam Tabel 1 berikut:

Tabel 1. Hasil analisis regresi

\begin{tabular}{|c|c|c|c|c|c|}
\hline \multicolumn{2}{|l|}{ Variabel } & \multirow{2}{*}{$\begin{array}{l}\begin{array}{c}\text { Koefisien } \\
\text { Regresi (B) }\end{array} \\
-2,865\end{array}$} & \multirow{2}{*}{$\begin{array}{c}\text { Standar } \\
\text { Beta }\end{array}$} & \multirow{2}{*}{$\begin{array}{l}\text { t-statistik } \\
-1,374\end{array}$} & \multirow{2}{*}{$\begin{array}{c}\text { Sig } \\
0,171\end{array}$} \\
\hline Constant & & & & & \\
\hline & $\mathrm{X} 1$ & 0,276 & 0,104 & 1,729 & 0,085 \\
\hline & $\mathrm{X} 2$ & 0,294 & 0,119 & 1,917 & 0,057 \\
\hline & $\mathrm{X} 3$ & 0,315 & 0,139 & 2,064 & 0,040 \\
\hline & $\mathrm{X} 4$ & 0,372 & 0,156 & 2,703 & 0,007 \\
\hline & X5 & 0,953 & 0,476 & 9,020 & 0,004 \\
\hline $\mathrm{R}$ & $=0,750$ & & & & \\
\hline $\mathrm{R}_{\text {Square }}=$ & $=0,563$ & & & & \\
\hline $\mathrm{F}_{\text {hitung }}=$ & $=50,026$ & & & & \\
\hline $\mathrm{N}=$ & $=200$ & & & & \\
\hline
\end{tabular}


Berdasarkan hasil analisis regresi di atas diperoleh harga koefisien regresi $b 1=0,276, b 2=0,294$, b3 $=0,315$, $\mathrm{b} 4=0,372$, dan $\mathrm{b} 5=0,953$, sedangkan nilai konstanta sebesar $£ 2,865$. Harga-harga tersebut dapat ditulis dalam bentuk model persamaan regresi sebagai berikut:

$$
\begin{aligned}
\mathrm{Y}= & \mathrm{a}+\mathrm{b} 1 \mathrm{X} 1+\mathrm{b} 2 \mathrm{X} 2+\mathrm{b} 3 \mathrm{X} 3+\mathrm{b} 4 \mathrm{X} 4+\mathrm{b} 5 \mathrm{X} 5 \\
\mathrm{Y}= & -2,865+0,276 \times 1+0,294 \times 2+0,315 \times 3+ \\
& 0,372 \times 4+0,953 \times 5
\end{aligned}
$$

Berdasarkan Tabel 1, terlihat adanya variabel-variabel bebas yaitu variabel X1 (layanan yang handal), variabel X2 (layanan yang responsif), variabel X3 (layanan yang meyakinkan), variabel X4 (layanan yang empatis), dan variabel X5 (layanan penyediaan fasilitas) berbeda signifikan. Dengan menggunakan tingkat kesalahan $5 \%$, berarti tidak semua variabel bebas tersebut secara parsial berpengaruh terhadap variabel terikat $\mathrm{Y}$ (kepuasan peserta didik), namun hanya variabel X3, X4 dan X5 yang berpengaruh terhadap Y, sedangkan variabel X1 dan X 2 tidak berpengaruh terhadap variabel $\mathrm{Y}$. Berdasarkan hasil analisis regresi ganda, layanan yang handal (X1) tidak mempunyai pengaruh secara signifikan terhadap kepuasan peserta didik (Y), karena variabel layanan yang handal (X1) dengan nilai $\mathrm{t}$ hitung lebih kecil dari tabel $\left(1,729 \_1,960\right)$ dengan probabilitas variabel X 1(0,085) lebih besar dari taraf signifikan 0,05. Sehingga pada tingkat kesalahan $=0,05$ layanan yang handal tidak berpengaruh terhadap kepuasan peserta didik. Berdasarkan hasil analisis regresi ganda, layanan yang responsif (X2) tidak mempunyai pengaruh secara signifikan terhadap kepuasan peserta didik (Y), karena variabel layanan yang responsif (X2) dengan nilai thitunglebih kecil dari t tabel $(1,917$ 1,960) dengan probabilitas variabel X $1(0,057)$ lebih besar dari taraf signifikan 0,05. Sehingga pada tingkat kesalahan 0,05 layanan yang responsif tidak berpengaruh terhadap kepuasan peserta didik.

Berdasarkan hasil analisis regresi berganda, layanan yang meyakinkan (X3) mempunyai pengaruh secara signifikan terhadap kepuasan peserta didik (Y), karena variabel layanan yang meyakinkan $(\mathrm{X} 3)$ dengan nilai $\mathrm{t}$ hitung lebih besar dari t tabel dengan probabilitas variabel X $3(0,040)$ lebih kecil dari taraf signifikan 0,05 . Hal ini diperkuat dengan hasil analisis korelasi parsial yang menunjukkan bahwa layanan yang meyakinkan mempunyai hubungan terhadap kepuasan peserta didik sebesar 0,147 , ini memberikan arti bahwa semakin tinggi layanan jaminan semakin tinggi pula kepuasan peserta didik. Koefisien determinan 0,0216. Ini berarti bahwa layanan yang meyakinkan memberi sumbangan sebesar 2,16\% terhadap kepuasan siswa.

Berdasarkan hasil analisis regresi berganda, layanan yang empatis (X4) mempunyai pengaruh secara signifikan terhadap kepuasan peserta didik (Y), karena variabel layanan yang empatis (X4) dengan nilai $t$ hitung lebih besar dari $\mathrm{t}$ tabel dengan probabilitas variabel X3 $(0,007)$ lebih kecil dari taraf signifikan 0,05 . Hal ini diperkuat dengan hasil analisis korelasi parsial yang menunjukkan bahwa layanan yang empatis mempunyai hubungan terhadap kepuasan peserta didik sebesar 0,191, ini memberikan arti bahwa semakin tinggi layanan yang empatis semakin tinggi pula kepuasan peserta didik. Koefisien determinan 0,0365, ini berarti bahwa layanan yang empatis memberi sumbangan sebesar 3,65\% terhadap kepuasan peserta didik. Layanan penyediaan fasilitas (X5).

Berdasarkan hasil analisis regresi ganda, layanan penyediaan fasilitas (X5) mempunyai pengaruh secara signifikan terhadap kepuasan peserta didik (Y), karena variabel layanan penyediaan fasilitas (X5) dengan nilai t hitung lebih besar dari t tabel dengan probabilitas variabel X5 lebih kecil dari taraf signifikan 0,05. Hal ini diperkuat dengan hasil analisis korelasi parsial yang menunjukkan bahwa layanan penyediaan fasilitas mempunyai hubungan terhadap kepuasan peserta didik sebesar 0,544, ini memberikan arti bahwa semakin tinggi layanan penyediaan fasilitas semakin tinggi pula kepuasan peserta didik. Koefisien determinan 0,296. Ini berarti bahwa layanan penyediaan fasilitas memberi sumbangan sebesar $29,60 \%$ terhadap kepuasan peserta didik.

\section{Kesimpulan}

Berdasarkan hasil analisis diketahui bahwa variabel layanan yang paling dominan mempengaruhi kepuasan peserta didik adalah layanan penyediaan fasilitas dengan koefisien regresi 0,953. Layanan ini berupa kebersihan lingkungan madrasah, kenyamanan ruang belajar, ketersediaan buku perpustakaan, ketersediaan sarana laboratorium, dan kelengkapan sarana atau alat pembelajaran. Dengan demikian, jika layanan penyediaan fasilitas ini ditingkatkan, maka akan semakin menambah kepuasan bagi para peserta didik. Disisi lain, layanan yang berupa ketepatan aturan akademik, relevansi kurikulum dengan kebutuhan, kesesuaian materi pembelajaran dengan silabus, kejelasan guru dalam memberi materi pembelajaran, kesiapan guru mengajar, kesiapan wali kelas dalam perwalian dan menanggapi keluhan siswa, yang termasuk dalam layanan yang handal dan layanan yang responsif secara parsial tidak mempunyai pengaruh secara signifikan terhadap kepuasan peserta didik apabila menggunakan tingkat kesalahan 5\%. Hal ini disebabkan karena layanan-layanan tersebut merupakan layanan yang sudah biasa diterima siswa. Jadi, walaupun layanan ini ditingkatkan tidak akan menambah kepuasan bagi para peserta didik. Namun apabila layanan yang handal dan layanan yang responsif ini diberikan secara bersama-sama dengan layanan yang meyakinkan, layanan yang empatis, dan layanan penyediaan fasilitas, maka akan memberikan pengaruh terhadap peningkatan kepuasan peserta didik. 


\section{DAFTAR PUSTAKA}

Adrian, Payne. 2000. The Essence Of Servce Marketing; Alih Bahasa, Fandy Tjiptono Edisi II-Yogyakarta: Andi .

Al-Husin, syahri. 2003. Aplikasi Statistik dengan SPSS. 11.0 For Windows. Yogyakarta:Graha Ilmu.

Ary Donald, Ary Furchon. Introduction to Research In Education. New York: Holt, Rinehart and Winston, 2004

Boediono, Koster, Wayan. 2001. Teori dan Aplikasi Statistik dan Probabilitas. Bandung:PT Remaja Rosdakarya

Buchari Alma. 2008. Manajemen Pemasaran dan Pemasaran Jasa. Bandung : Alfabeta

Dewi Sartika, I. 2002. Quality Service In Education. Edisi Khusus Untuk Kalangan Mahasiswa, Bandung: Kantor Yayasan Potensia.

Depdiknas. 2004. Manajemen Mutu Berbasais Sekolah . Jakarta: Dirjen Dikdasmen.

Depdikbud. 1993. Himpunan Keputusan Menteri Pendidikan dan Kebudayaan Republik Indonesia. Jakarta: Sekjen Biro Keuangan.

Depdiknas (2004). Peningkatan Kinerja Kepala Sekolah. London: Depdiknas Dirjen Dikdasman

Djamaluddin Ancok, Teknik Penyusunan Skala Pengukuran; PPK UGM, Yogyakarta, 1989.

Furchan, A. 2004. Pengantar Penelitian dalam Pendidikan. Yogyakarta : Pustaka Pelajar

Gaspersz, Vincent, 2003, Management Kualitas, Yayasan Indonesia Emas dan Gramedia, Pustaka Pelajar:Jakarta

Hadi, S. 1976, Metodologi Research, Jilid I. Yogyakarta : Yayasan Penerbit Fakultas Psikologi Universitas Gajah Mada.
Lewis, R.C. and B.H Booms. 1983. The Marketing Aspect of Service Quality, Chicago:American Marketing Association, pp. 99-107

Mulyasa, E. 2003. Manajemen Berbasis Sekolah. Bandung.Rosda.

Raharjo, Budi. Depdiknas. (2003). Manajemen Berbasis Sekolah (MBS), Jakarta:Balai Pustaka.

Sallis E. 2007. Total Quality Management in Education. Jogjakarta: Ircisod.

Sugiyono, 2005. Metode Penelitian Administrasi, Bandung: Alfabeta.

Raymond F, Zammuto. 2008. The Competing Values Framework : Understanding the Impact of OrganizationalCulture on the Quality ofWork Life. Organization Development Journal, 19(3) hal 58-59

Soetjipto, 1999 Profesi Keguruan, Jakarta : Proyek Peningkatan Mutu Tenaga Kependidikan, Depdiknas. Jakarta

Sopiatin, Popi. 2010. Manajemen Belajar Berbasis Kepuasan Siswa, Bogor: Ghalih Indonesia

Tenner, AR; DeToro, IJ. 1992. Total Quality Management: Three Steps to Continuous Improvement. Addison-Wesley Publishing Company, Massachusetts.

Tjiptono, Fandy dan Anastasia Diana. 2003; Total Quality Management (TQM),Yogyakarta: Andi

Tjiptono, Fandy danAnastasia Diana. 2005; Service, quality, and satisfaction, Yogyakarta : Andi Offset

Udin Saefudin Sa'ud. 2008; Inovasi Pendidikan, Bandung: Alfabeta 